\title{
UMA REVISTA DE CULTURA NUM PAÍS DE INTOLERÂNCIA POLIITICA A PUBLICAÇÃO COLOMBIANA MITO COMO OBJETO POLÍTICO
}

Vítor Kawakami

USP

RESUMO: Através de uma abordagem que busque compreender as dimensões culturais e políticas como interdependentes, com 0 aux́lio de embasamentos conceituais de pensadores como Raymond Williams, Beatriz Sarlo e Michel Foucault, este artigo discute a forma como Mito - revista bimestral de cultura atuou diretamente sobre a polarizada e conflitante realidade política colombiana entre os anos de 1955 e 1962, posicionando-se diante de entraves socioculturais que perduravam desde os anos diretamente anteriores a sua publicação. A perspectiva de leitura considerada, antes de tomar a revista apenas como registro de acontecimentos históricos, observa a composição de seu discurso enquanto interferente no contexto político-cultural do país.

PALAVRAS-CHAVE: Literatura colombiana. Periódicos literários latino-americanos. Intelectuais e política.

\section{A MAGAZINE OF CULTURE IN A COUNTRY WITH POLITICAL INTOLERANCE THE COLOMBIAN PERIODICAL MITO AS POLITICAL OBJECT}

ABSTRACT: Through an approach that seeks to understand the cultural and political dimensions as interdependent, based on conceptual emplacements of thinkers as Raymond Williams, Beatriz Sarlo and Michel Foucault, this article discusses how Mito - revista bimestral de cultura worked directly on the polarized and conflicting Colombian political reality between the years of 1955 and 1962, positioning itself on the socio-cultural barriers that lingered from the years directly prior to its publication. The considered reading perspective, before taking the magazine only as a record of historical events, notes the composition of its speech as interfering in the political-cultural context of the country.

KEYWORDS: Colombian literature. Latin-American literary periodicals. Intellectuals and politics.

Vítor Kawakami é mestre em Letras pela Universidade de São Paulo. 


\title{
UMA REVISTA DE CULTURA NUM PAIIS DE INTOLERÂNCIA POLÍTICA A PUBLICAÇÃO COLOMBIANA MITO COMO OBJETO POLÍTICO
}

\author{
Vítor Kawakami
}

\section{O CONTINUUM POLÍTICO-CULTURAL}

Uma das frases mais repetidas e famosas de Jorge Gaitán Durán, principal mentor de Mito - revista bimestral de cultura, curiosamente não vem de algum verso dos seus conhecidos poemas, mas sim de um texto por ele escrito para ser lido durante a homenagem aos 95 anos de Baldomero Sanín Cano ocorrida na Universidade de América em agosto de 1956: "Hay que acabar con la idea monstruosamente banal de que la calidad intelectual es independiente de la calidad humana. Todo edificio estético descansa sobre un proyecto ético."1 Em outros trechos desse discurso que serve de estímulo para Gaitán Durán discorrer sobre temas delicados à realidade colombiana como as relações entre cultura e educação, a censura à liberdade de opinião ou como a responsabilidade dos intelectuais, podemos encontrar importantes reflexões que remetem às raízes da violência no país:

[...] Hoy en día nuestra gran tara nacional es la intolerancia. En Colombia reinan la intolerancia política, la intolerancia religiosa, la intolerancia moral. [...] Sin libertad de crítica, sin libertad de conocimiento, sin libertad de examen, sin libertad de cátedra [...] se pasa automáticamente del terreno de las ideas al terreno de la violencia. Lo que no puede ser resuelto por la expresión libre de las opiniones contrarias, se resuelve por medio de la fuerza o del choque armado. La tolerancia no es sólo el caldo de cultivo de la cultura, sino también su vehículo. Ante la censura, brutal o refinada, el intelectual se aisla, se repliega, se incomunica. La expresión queda trunca, separada del pueblo. El intelectual no puede cumplir ni su tarea creativa, ni su tarea educativa, que, por lo demás, están orgánicamente enlazadas. La intolerancia le prohibe el acceso a las fuentes de la cultura. Y al mismo tiempo le prohibe al hombre el acceso a sus fuentes vitales.

\footnotetext{
${ }^{1}$ DURÁN, Jorge Gaitán. Sanín Cano y la situación del intelectual colombiano. Lecturas Dominicales de Intermedio, Bogotá, p. 11, 19 maio 1957. Vale ressaltar que Intermedio foi o nome adotado temporariamente pelo jornal El Tiempo depois que foram suspensos pela censura, no decorrer do segundo semestre de 1955, os principais jornais do país (como também El Espectador e El Siglo) em uma clara ação de intolerância do governo militar de Rojas Pinilla.
} 
Durante os anos 50, Colômbia viveu os reflexos diretos, certamente, de problemas cruciais que não haviam sido resolvidos em anos anteriores. Identificar uma possível origem dos "ódios herdados" por seu povo década após década de violência sem limites é também tarefa ilimitada, ou, no mínimo, levaria às origens sociais e políticas do país. Ao período que se convencionou chamar de la Violencia e que abarca os anos de 1946 a 1957 segundo a maioria dos historiadores, muito já se buscou para tentar encontrar motivos, razões ou origens de tanta intolerância. Para um estudo sobre Mito, traçar algumas ideias acerca dos acontecimentos históricos que antecederam e atravessaram o surgimento da revista fundada por Jorge Gaitán Durán e Hernando Valencia Goelkel se mostra como um de seus alicerces investigativos primordiais, levando-se em conta que esta publicação periódica, mesmo que pensada principalmente como uma revista de literatura, procurou manifestar em suas páginas durante seus sete anos de existência (abril de 1955 a junho de 1962) algumas posturas de intelectuais de diferentes tendências políticas frente aos principais problemas nacionais. Consideramos fundamental abordar Mito a partir de uma discussão sobre fenômenos político-sociais como, por exemplo, o que diz respeito ao período de la Violencia e a maneira através da qual a revista construiu o imaginário político em suas páginas, tomando isso não apenas como uma afirmação de causalidade reflexiva entre tais fenômenos e a produção literária da revista, mas sim como uma ênfase à textualidade e sua função no contexto político-social. Além disso, fortalece essa abordagem o fato de que em anos anteriores ao surgimento da revista seus futuros gestores já vinham participando de acontecimentos significativos do período (por exemplo, Jorge Gaitán Durán no Bogotazo em 1948, Pedro Gómez Valderrama ao lado de Carlos Lleras Restrepo no atentado à casa deste político liberal em 1952², Eduardo Cote Lamus por sua proximidade à ditadura de Rojas Pinilla em $1954^{3}$ ) ou haviam se manifestado, através de diversos periódicos e revistas culturais, sobre a crise política colombiana.

Portanto, e partindo desse pressuposto, o que significava publicar uma revista de cultura num contexto sociocultural retrógrado e politicamente desfavorável? Como buscamos mostrar ainda que brevemente neste artigo, a relação

\footnotetext{
2 Informação fornecida por Pedro Alejo Gómez Vila, filho de Pedro Gómez Valderrama, em Bogotá, no dia 30 de julho de 2014.

${ }^{3}$ Eduardo Cote Lamus, muito próximo ao líder conservador do Norte de Santander, Lucio Pabón Núñez, Ministro das Relações Exteriores do governo do general Rojas Pinilla, foi nomeado Cônsul auxiliar na Alemanha em 1954.
} 
entre literatura e política se mostrava inevitável, sobretudo porque, além da conjuntura nacional que exigia mudanças na relação entre intelectuais e suas formas de atuar (ou não) na sociedade, também as discussões sobre essa relação vinham numa crescente tendência no âmbito internacional à qual os fundadores da revista estavam atentos, como é o caso da influência do existencialismo francês e o modelo sartreano do intelectual engagé. Era latente a necessidade de recuperar a dignidade intelectual da Colômbia, como bem observou Rafael Gutiérrez Girardot ${ }^{4}$, após o caos instalado com o assassinato de Jorge Eliécer Gaitán em 1948. Além disso, algo que nos parece um grande acerto de consciência crítica verificada por Gaitán Durán e seu grupo ao proporem a publicação de uma revista dita "cultural", é que assim eles estavam necessariamente estabelecendo relações com o âmbito da "política" enquanto experiência do real, enquanto modo de lidar com os acontecimentos em seu momento presente, vinculando-se à ideia de "cultura" - amplo conjunto de conhecimentos que distinguem um determinado grupo social e suas práticas simbólicas ${ }^{5}-$ por meio de ações, criações e pensamentos diretamente vinculados à realidade de seu momento de publicação. A constatação na época por parte dos responsáveis pela revista da necessidade de abertura do país à cultura universal — fato que hoje em dia é tomado pela intelectualidade colombiana como um dos maiores feitos de Mito, o de ter colaborado com a modernização cultural do país , justamente só foi possível, a nosso ver, graças à forte presença entre eles da compreensão da "cultura" como algo indissociável da "política". ${ }^{6}$

4 GIRARDOT, Rafael Gutiérrez. Mito: asomo nacional a la modernidad. El Tiempo, Bogotá, 21 abr. 2005. (Sección Lecturas).

${ }^{5}$ Ainda que em seus números Mito não tenha especificamente se ocupado de refletir conceitualmente sobre aquilo que a revista anunciava como o seu campo de atuação, a saber, o da "cultura" em si, o imaginário apresentado de forma horizontal abriu-se para uma compreensão da sua noção como um amplo espectro de manifestações (cinema, sociologia, história, artes plásticas, teatro, filosofia, etc.) às quais a revista procurou manter-se ocupada. Sobre essa ideia de amplificação horizontal da cultura, ver a entrevista de Gaitán Durán a Fernán Torres León “'El país está saliendo del feudalismo', opina el escritor Jorge Gaitán Durán”, publicada em 5 de abril de 1959, p. 3, em Lecturas dominicales de El Tiempo, apud DURÁN, Jorge Gaitán; GÓMEZ, Mauricio Ramírez. Un solo incendio por la noche. Bogotá: Casa de Poesía Silva, 2004, p. 189-190.

6 O papel de Mito dentro da modernização cultural da Colômbia percorre boa parte da fortuna crítica sobre a revista: de Juan Gustavo Cobo Borda ("Lectura de Mito", em Mito, 1955-1962 - Selección de textos. Bogotá: Instituto Colombiano de Cultura, 1975), passando por Rafael Gutiérrez Girardot ("La literatura colombiana en el siglo XX", em Ensayos sobre literatura colombiana I. Medellín: Unaula, 2011), até chegar às leituras mais atuais como as de Pedro Sandoval (La revista Mito en el tránsito de la modernidad a la posmodernidad literaria en Colombia. Bogotá: Caro y Cuervo, 2006) e Carlos Rivas Polo (Revista Mito: vigencia de un legado intelectual. Medellín: Editorial Udea, 2010), bastante focadas no interesse de Mito pela cultura 
Em um já célebre e bastante referenciado texto escrito por Beatriz Sarlo, "Intelectuales y revistas: razones de una práctica", a intelectual argentina, reconhecida por seu trabalho na revista Punto de Vista, emite seu parecer em relação ao tipo de leitura crítica sobre uma revista:

\begin{abstract}
Entre todas las modalidades de intervención cultural, la revista pone el acento sobre lo público, imaginado como espacio de alineamiento y conflicto. Su tiempo es, por eso, el presente. Aunque luego la historia pueda desmentirlo, las revistas no se planean para alcanzar el reconocimiento futuro (positiva fatalidad que puede sucederles) sino para la escucha contemporánea.

[...]

Resistiéndose a una perspectiva crítica formalista, las revistas parecen objetos más adecuados a la lectura socio-histórica: son un lugar y una organización de discursos diferentes, un mapa de las relaciones intelectuales, con sus clivajes de edad e ideologías, una red de comunicación entre la dimensión cultural y la política. ${ }^{7}$
\end{abstract}

Seguindo o caminho apontado por Sarlo, a noção de "cultura" que aqui nos interessa provém de uma concepção de influência williamsiana ${ }^{8}$ que a identifica com os modos que uma comunidade ou indivíduo respondem as suas necessidades simbólicas, considerando para isso as práticas culturais e os instrumentos desse processo, e que configuram um estado de espírito ou comportamento

universal e pelos importantes autores traduzidos e publicados em suas páginas. A proposta de leitura de Mito pautada na indissociabilidade entre "cultura" e "política" é uma das bases de minha pesquisa de mestrado $A$ revista colombiana Mito e os alcances do seu discurso políticocultural (2016. Dissertação (Mestrado em Letras) - Faculdade de Filosofia, Letras e Ciências Humanas, Universidade de São Paulo).

7 SARLO, Beatriz. Intelectuales y revistas: razones de una práctica. Cahiers du Criccal, Paris, n. 9-10, p. 9 e 15, jan. 1992.

8 Nosso interesse na forma como Raymond Williams procurou abordar essa questão, sobretudo em um trabalho como The long revolution (1961) ou nas posteriores reflexões de $A$ política $e$ as letras (1979), baseia-se inicialmente na conotação que considera o sentido de cultura como um processo, chamando a atenção para seu significado histórico inicial atribuído à ideia de cultivo de algo, de uma atividade de movimento através de um período de tempo, algo que aproximaria o conceito de cultura como "todo um modo de vida" (p. 150). Procurando mostrar o quanto a prática econômico-política se torna determinante no resto da vida real, Williams chegou à verificação da "formulação da ideia de produção cultural como material em si" (p. 133), ou seja, a produção cultural passou a ser vista como social e material, assim levando-o à ideia de "indissociabilidade do processo social" (p. 134). E é sobretudo a essa consciência da "indissolubilidade de todo processo sociomaterial" (p. 134) que aqui nos dedicamos enquanto base conceitual (p. 132): a de "inseparabilidade das estruturas - as relações inextricáveis entre política, arte, economia e organização familiar", o que ele identificou como "elementos indissolúveis de um processo sociomaterial contínuo". WILLIAMS, Raymond. A política e as letras: entrevistas da New Left Review. São Paulo: Editora Unesp, 2013. 
coletivo. Teixeira Coelho', ao reconhecer dois diferentes ângulos de abordagem a tal noção, como o seriam um "idealista", "que vê no termo cultura o índice de um espírito formador global da vida individual e coletiva a manifestarse numa variedade de comportamentos e atos sociais", e outro "materialista", "que considera a cultura - em todos os seus aspectos, incluindo os relacionados a todos os media e construções intelectuais - como reflexo de um universo social mais amplo e determinante", mostra que uma tendência dominante nas últimas décadas seria uma composição entre esses dois modos de entendimento: "[...] as várias manifestações culturais não são determinadas de modo absoluto por uma ordem social global patente [...], mas são elementos decisivos na definição daquela ordem." Nossa intenção aqui é buscar seguir com uma leitura de Mito que melhor se adéque a essa tendência, pois, ao que nos parece, seria a mais aproximada da ideia de "cultura" entendida pela revista colombiana: a Mito mostrou-se necessária uma abertura à "ordem global" (ou melhor, "universal") com o intuito de possibilitar discutir em um mesmo nível os temas próprios da conjuntura cultural interna a que se encontrava inserida - e que seus realizadores os julgaram como essenciais -, e assim poder, numa instância contemporânea, participar na "definição daquela ordem".

Mito - revista bimestral de cultura foi uma publicação periódica colombiana que soube reunir em seus 42 números uma significativa representatividade intelectual de dentro e de fora do país, habilmente articulada por jovens escritores como Jorge Gaitán Durán e Hernando Valencia Goelkel, seus fundadores, lançando o primeiro número em abril/maio de 1955, mas também sob a égide de outros promissores escritores como Eduardo Cote Lamus, Pedro Gómez Valderrama, Rafael Gutiérrez Girardot, Fernando Charry Lara e Jorge Eliécer Ruiz. Juntos constituíram um grupo de suporte responsável não apenas por sua orientação literária como também por sua coordenação redacional (com exceção de Gutiérrez Girardot e somando-se Eduardo Mendoza Varela a essa direção), assumindo uma rotatividade nos cuidados com a revista e alcançando razoável período de duração. Se levarmos em conta que revistas culturais de origem microempresarial privada como Mito na Colômbia até a metade do século $\mathrm{XX}$ dificilmente duravam tanto tempo, tal rotatividade acabou por favorecer que seus responsáveis exercessem atividades profissionais paralelas, sobretudo

${ }^{9}$ COELHO, Teixeira. Dicionário crítico de política cultural. São Paulo: lluminuras, 1997, p. 103104. 
político-administrativas ${ }^{10}$, assim como as dedicadas à produção literária individual. Durante os sete anos em que a revista alcançou considerável importância como periódico cultural, não somente o país passava por mudanças cruciais dentro de sua organização social, cultural, política e econômica, como também inúmeros rearranjos da mesma ordem na conjuntura global afetavam países periféricos no cenário internacional como a Colômbia.

A concepção de uma atuação editorial em âmbito vasto como o cultural abriu um leque de matérias que possibilitou que inúmeros escritores e artistas de diferentes tendências estéticas ou ideológicas encontrassem na publicação um meio de divulgação de seus trabalhos, fossem eles ensaios, poemas, narrativas ou resenhas críticas. Além disso, também chama a atenção o fato de que Mito conseguiu conciliar diferentes gerações de intelectuais, cujas presenças, desde figuras como Hernando Téllez ou León de Greiff, que já vinham de experiências decisivas no cenário cultural colombiano, até importantes personalidades da literatura internacional como Octavio Paz, Alfonso Reyes, Jorge Luís Borges, Vicente Aleixandre, Carlos Drummond de Andrade ou Luis Cardoza y Aragón, para citar apenas alguns nomes dos que a apoiaram principalmente desde seu comitê patrocinador, comprovam este fecundo encontro geracional, cuja nômina era ainda composta de jovens escritores como Andrés Holguín, Héctor Rojas Herazo ou Marta Traba, para exemplificar. Não podemos deixar de ver nessa articulação intelectual um proveitoso resultado do talento político-literário do grupo liderado por Gaitán Durán, ainda corroborando a ideia de que o trabalho de Mito pode ser lido como uma espécie de ajuste histórico em prol da modernização cultural no país a que convergiram pensamentos de diferentes princípios e inclinações, inclusive se pensarmos tal ajuste sob uma óptica pragmática (e até mesmo cética em relação ao protagonismo da revista)

\footnotetext{
10 Dentre os participantes da revista, Eduardo Cote Lamus foi Cônsul, Congressista, Secretário de Educação do departamento de Norte de Santander, Senador e Governador do Norte de Santander; Jorge Gaitán Durán participou do Movimiento Revolucionario Liberal - MRL e tentou se eleger como Congressista; Pedro Gómez Valderrama foi Conselheiro de Estado, Ministro de Governo e de Educação, Embaixador na Organização de Estados Americanos OEA, na Espanha e na antiga URSS; Rafael Gutiérrez Girardot foi adido cultural da embaixada na Alemanha e trabalhou no Ministério de Relações Exteriores em Bogotá; Jorge Eliécer Ruiz foi subdiretor de Colcultura, Secretário geral do Ministério da Educação, consultor da Unesco e das Nações Unidas, conselheiro cultural dos Presidentes Belisario Betancur e Virgilio Barco; Hernando Valencia Goelkel foi também conselheiro do Presidente Betancur e diretor de Colcultura.
} 
como a do crítico francês Jacques Gilard ${ }^{11}$ ao encará-lo como resultado de um "contexto que era de reflexión sobre qué y cómo reconstruir" após o derrubamento social vivido pelo país desde o fim dos anos 40.

\section{CONDICIONAMENTOS HISTÓRICOS E PRÁXIS}

No que diz respeito aos condicionamentos históricos internos ao país circunstâncias geradas por acontecimentos políticos, sociais e econômicos dentro de um recorte temporal contemporâneo à publicação da revista - e que deles aqui nos servimos para melhor compreender de que maneira Mito configurou o imaginário político-cultural de sua época de atuação, apoiamo-nos principalmente em três temas inter-relacionados: o bipartidarismo político entre liberais e conservadores como uma das principais bases conflitantes; a persistência do fenômeno social de la Violencia cujo estampido do Bogotazo pode ser visto como um marco divisor na história política do país; e os processos totalitários que geraram os períodos de ditaduras civil e militar e que foram o contexto imediato do surgimento da revista. Esses motivos, pela forma como Mito os discutiu e neles procurou intervir direta ou indiretamente, propondo e estabelecendo aquilo que seus idealizadores entendiam como práxis intelectual, servem para nos ajudar a sustentar uma abordagem política sobre a publicação, sem deixar de proporcionar observações de como se deram as relações com a literatura ou demais manifestações de âmbito cultural.

Sobre a ideia de "historicidade" implicada no discurso político-cultural da revista Mito, apoiamo-nos no aspecto também de indissociabilidade que ela traz da noção de "acontecimentos" e das relações de força entre eles, tendo em vista a estreiteza de vinculação entre os termos "acontecimento" e "política". Michel Foucault, ao refletir sobre a oposição suscitada a partir dos conceitos de "estrutura" e "acontecimento", atentou para o fato de que: "O problema é ao mesmo tempo distinguir os acontecimentos, diferenciar as redes e os níveis a que pertencem e reconstituir os fios que os ligam e que fazem com que se engendrem, uns a partir dos outros", assim justificando "o recurso às análises que se fazem em termos de genealogia das relações de força, de desenvolvimentos

${ }^{11}$ GILARD, Jacques. Para desmistificar a Mito. Estudios de Literatura Colombiana, Medellín: Universidad de Antioquia, n. 17, p. 29, jul.-dez. 2005. (Dosier Mito Revista Bimestral de Cultura). 
estratégicos e de táticas." ${ }^{12}$ Pois bem, pautar uma leitura histórica resultante de confrontos entre tipos de "acontecimentos" diferentes e muitas vezes inclusive oposicionistas, e assim estabelecer uma composição sustentada pela trama genealógica de "relações de forças", seria, pelo nosso modo de ver, justamente ratificar a existência de um interior comum a conceitos como os de "historicidade", de "acontecimento" e de "política". Uma análise histórica, nesse sentido, portanto, seria necessariamente uma análise política:

\begin{abstract}
A historicidade que nos domina e nos determina é belicosa e não linguística. Relação de poder, não relação de sentido. A história não tem "sentido", o que não quer dizer que seja absurda ou incoerente. Ao contrário, é inteligível e deve poder ser analisada em seus menores detalhes, mas segundo a inteligibilidade das lutas, das estratégias, das táticas. ${ }^{13}$
\end{abstract}

Examinar uma revista como Mito a partir de uma abordagem sócio-histórica que leve em consideração as relações de "poder"14 presentes na "historicidade", assim nos propicia discutir não somente os acontecimentos políticos da época a que coube à revista pertencer, mas, sobretudo, discutir a maneira que Ihe coube intervir na configuração do "imaginário político" colombiano ao se incorporar ativamente aos acontecimentos da época. Daía importância de uma leitura que leve em consideração a revista não como fonte histórica, mas sim como objeto histórico que procurou participar politicamente no interior "das lutas, das estratégias, das táticas".

\title{
DIÁLOGO FUNDAMENTAL
}

Uma primeira constatação que podemos notar em função do imaginário político proposto por Mito é a de que em suas páginas o bipartidarismo político assumiu contornos pautados na busca de uma tolerância diante de convicções ideológicas não convergentes, ou inclusive oposicionistas, entre seus colabora-

\footnotetext{
12 FOUCAULT, Michel. Verdade e poder. In:. Microfísica do poder. Rio de Janeiro: Graal, 2003, p. 5.

13 Ibidem.

${ }^{14}$ Ao discorrer sobre a vasta definição de "política", Norberto Bobbio, além de identificá-la em sua concepção moderna para indicar o conjunto de atividades que tem como referência o Estado, procura mostrar o quanto a ideia de "política" enquanto práxis humana está estreitamente ligada ao conceito de "poder". Cf. BOBBIO, Norberto; MATTEUCCI, Nicola; PASQUINO, Gianfranco. Dicionário de política. v. 1. Brasília: Editora UnB, 1998, p. 954.
} 
dores ou realizadores. A solução encontrada por Mito diante da divergência política de seus realizadores nos parece no mínimo estratégica. Em seu texto publicado em Mito, "La comedia de las contradicciones liberales", em forma de carta crítica à revista, Jorge Child afirma "que en la dirección de MITO hay representantes de todas las tendencias: dos conservadores, un liberal de centro y un hombre suelto a quienes 'los comunistas llaman reaccionario y viceversa'"15, e apesar da arbitrariedade desta classificação que foi comentada pelos próprios diretores, sabemos que aponta para o fato reconhecido das diferenças políticas entre Gaitán Durán, Valencia Goelkel, Gómez Valderrama e Cote Lamus, responsáveis pela revista na época. A convivência ideológica encontrada por seus realizadores dentro do próprio grupo assim como através da publicação inclusive de textos detratores como a própria carta de Child, nos parece, sem dúvida, um bivalente exemplo de postura conciliadora diante de tantos casos de contradições políticas que predominavam no país há décadas. De acordo com as palavras de Gutiérrez Girardot:

La revista no se adhirió a una determinada ideología ni a determinados intereses y vanidades políticas. Sus colaboradores eran de todos los colores, si así cabe decir: de izquierda, de conservatismo provinciano, de liberalismo moderado, apolíticos. La calidad y la honradez intelectual eran el único mandamiento y el lazo humano que los unía. En un país de enemigas facciones políticas esto era una lección de moral ciudadana y nacional. Esta fue la sustancia que silenciosamente impulsó a los colaboradores a "conquistar, merecer la patria", como dijo Alfonso Reyes sobre la esencia del patriotismo auténtico. ${ }^{16}$

Mas a nova relação com a pátria, mencionada acima por Gutiérrez Girardot cinquenta anos depois de lançado o primeiro número de Mito, em abril de 1955 ainda estava sendo dada em seus primeiros passos e a resistência do povo à transição de uma Colômbia alicerçada em características retrógradas, remanescentes do século XIX (Estado - Igreja - economia agrária), para uma Colômbia moderna, laica e industrializada, era muito grande. A própria Igreja Católica, por exemplo, que no decorrer dos séculos XIX e XX havia se aproximado ideologi-

${ }_{15}$ CHILD, Jorge. La comedia de las contradicciones liberales. Mito - revista bimestral de cultura, Bogotá, n. 9, p. 196, ago.-set. 1956.

${ }^{16}$ GIRARDOT, Rafael Gutiérrez, Mito: asomo nacional a la modernidad, op. cit. 
camente do partido conservador, não mediu esforços belicosos em suas palavras $^{17}$ para questionar as mudanças empreendidas pelo governo liberal de Alfonso López Pumarejo através da reforma constitucional de 1936, ao tentar laicizar um pouco o Estado garantindo a liberdade de cultos e procurando desvincular a educação pública da alçada da religião católica. Alguns anos depois, em 1955, a revista Mito, numa ação revisora do opressivo poder que a moral católica imprimia sobre os colombianos, e, de alguma forma servindo-se dessa primeira abertura laica dos anos 30, causaria certo escândalo nos meios literários do país ao publicar como texto inicial da revista o "Diálogo entre un sacerdote y un moribundo", de Sade ${ }^{18}$, tocando habilmente numa ferida exposta da tradição cultural do país e atentando para a contemporaneidade do escritor francês. A publicação desse texto quase custou o registro editorial da revista junto ao Ministerio de Gobierno, que por sua vez aplicou uma multa alegando que Mito havia lesado o sentimento católico. ${ }^{19}$

\section{ANTICONFORMISMO E OS ÓDIOS HERDADOS}

Uma interessante e fundamental questão que deve também aqui ser mencionada é que Colômbia passou, após a Segunda Guerra Mundial, por profundas mudanças econômicas geradas pela produção cafeicultora que alcançou níveis nunca antes vistos. Segundo Darío Mesa, em seu texto publicado em Mito ( $N^{\circ}$ 13) chamado "Treinta años de nuestra historia", períodos de prosperidade econômica como esse permitiram o desenvolvimento modernizante da indústria do país, mas o impacto dessas mudanças na sociedade colombiana restringiuse a provocar a abertura de um massivo êxodo rural e consequente crescimento populacional dos principais centros urbanos, agora necessitados de mão de

17 Como é possível ler na carta pastoral dirigida ao Presidente da República pelo Arcebispo primado de Bogotá, assinada em conjunto com demais bispos do país quando da aprovação das reformas constitucionais de 1936: "Hacemos constar que nosotros y nuestro Clero no hemos provocado la lucha religiosa sino que hemos procurado mantener la paz de las conciencias aún a costa de grandes sacrificios; pero si el Congreso insiste en plantearnos el problema religioso, lo afrontaremos decididamente y defenderemos nuestra fe y la fe de nuestro pueblo a costa de toda clase de sacrificios, con la gracia de Dios (...)" apud MEJ́́A, Alvaro Tirado. Colombia: siglo y medio de bipartidismo. In: MELO, Jorge Orlando (Coord.). Colombia hoy Perspectivas hacia el siglo XXI. Bogotá: Tercer Mundo, 1997, p. 157-158.

${ }_{18} \mathrm{SADE}$, Donatien A. F. de. Diálogo entre un sacerdote y un moribundo. Mito - revista bimestral de cultura, Bogotá, n. 1, p. 11-19, abr.-maio 1955.

19 GÓMEZ, Mauricio Ramírez. Jorge Gaitán Durán: un mar que se ignora. Medellín: Editorial Universidad de Antioquia, 2013, p. 39. 
obra para a indústria que crescia. Os desentendimentos e contradições políticas da época são assim referidos por Mesa:

La contradicción entre el país agrario y semicolonial y la nación moderna y predominantemente burguesa empezaba a llegar al clímax [...]. Todo demandaba cambio, todo; pero la clase dirigente que, entre tanto, resistía a la ofensiva de las masas, no llegaba a ponerse de acuerdo sobre el alcance de las reformas. [...].

[...] Lo que se veía en la superficie, no obstante, era la lucha de los partidos tradicionales por el control del Estado. [...]. El espíritu de partido, determinado por la predominancia de los grupos burocráticos y por la fuerza de caudillos que no percibían claramente el cambio estructural de la nación y trataban, por eso, de someterla a esquemas más cercanos a la organización medioeval que al capitalismo, impedía frecuentemente su vinculación [...]. Los "odios heredados" se apoyaban en las vastas regiones donde la agricultura $\mathrm{y}$, en parte, la sociedad, permanecen al nivel del siglo XVI.20

Se levarmos em consideração que em 1938 a população urbana era de $31 \%$, em 1951 de 39\%, alcançando o patamar de 52\% somente em 1964", temos assim uma dimensão do tamanho da massa rural que compunha a maior parte da população colombiana em 1946, ano decisivo para o surgimento de la Violencia, e que nos leva a concordar com as seguintes palavras do colombianista David Bushnell:

Existen, por lo tanto, buenas razones para considerar la hereditaria rivalidad partidista entre liberales y conservadores como la causa principal de la Violencia. Los sucesos políticos habían desencadenado el proceso y las rivalidades políticas lo mantenían vigente. Pero la dramática intensidad de la competencia entre los partidos colombianos habría sido impensable si el nivel de desarrollo rural en términos sociales y económicos hubiera sido más alto. Solamente un campesinado semianalfabeto y con las más imprecisas ideas sobre lo que ocurría en el país se habría dejado convencer de que los miembros del partido contrario estaban aliados con el diablo [...].22

Um caso exemplar desse baixo nível de desenvolvimento social, sobretudo no campo, encontramos mais tarde nas páginas de Mito e sua visível busca por

${ }^{20}$ MESA, Darío. Treinta años de nuestra historia. Mito - revista bimestral de cultura, Bogotá, $\mathrm{n}$. 13, p. 61, mar.-abr.-maio 1957.

21 OCAMPO, José Antonio (Ed.). Historia económica de Colombia. Bogotá, 1987, p. 259 (tabela), apud BUSHNELL, David. La era de la Violencia (1946-1957). In: Colombia - Una nación a pesar de sí misma. 5. ed. Bogotá: Planeta Editorial, 2000, p. 285. (Colección La Línea del Horizonte).

22 BUSHNELL, David. La era de la Violencia (1946-1957), op. cit., p. 283. 
denunciar as misérias da realidade social colombiana, através de publicações de textos que, ainda que reconhecidamente acessíveis somente às minorias intelectuais do país, alcançaram definitivas marcas em sua linha editorial. As seções "Testimonios" ou "Documentos" trouxeram pequenos escândalos com textos revelando as consequências de uma educação repressora aliada a situações econômicas precárias, tratando de temas como crise no matrimônio, condições desumanas nos presídios ou repressão ao homossexualismo. Dentre eles, o que causou certamente maior impacto foi o texto de Humberto Salamanca Alba, "Historia de un matrimonio campesino"23, que acompanhado de impressionantes fotos trouxe o caso de jovem casal de trabalhadores rurais em que o marido costurava a vagina da esposa com arame farpado com medo que ela o traísse. Fatos como esse, resultantes de um precário nível de instrução e de um tradicionalismo arcaico repugnante, servem para exemplificar as difíceis condições sociais e culturais a que estavam submetidos os colombianos quando do surgimento da revista, e que advinham de estados de misérias igualmente herdados pelo povo por décadas.

Também interessante exemplo da forma como Mito procurou atuar frente às incongruências dos acontecimentos políticos de sua época se deu através da então recente memória do assassinato do líder liberal Jorge Eliécer Gaitán e o consequente estopim do Bogotazo. A atuação populista de Eliécer Gaitán no período que antecedeu seu assassinato em 1948 foi marcada por intensas denúncias e manifestações contra a violência que se alastrou pelo país depois da vitória do conservador Ospina Pérez na eleição presidencial. Porta-voz do descontentamento da grande massa diante do aumento dos custos de vida e dos inúmeros casos de violência, um de seus mais célebres discursos, "La Oración por la Paz", em 1958 foi publicado na íntegra pela revista Mito ${ }^{24}$ ( $\left.N^{\circ} 18\right)$, assim

${ }^{23}$ ALBA, Humberto Salamanca. Historia de un matrimonio campesino. Mito - revista bimestral de cultura, Bogotá, № 15, p. 201-224, ago.-set. 1957 e № 17, p. 352-377, dez. 1957 - jan. 1958.

${ }^{24}$ GAITÁN, Jorge Eliécer. La Oración por la Paz. Mito - revista bimestral de cultura, Bogotá, No 18, p. 497-498, fev.-mar.-abr. 1958. Nela podemos ler frases como as seguintes: "Impedid, señor presidente, la violencia. Solo os pedimos la defensa de la vida humana, que es lo menos que puede pedir un pueblo. En vez de esta ola de barbarie, podéis aprovechar nuestra capacidad laborante para beneficio del progreso de Colombia. [...]. Os decimos, excelentísimo señor presidente: Bienaventurados los que no ocultan la crueldad en su corazón, los que entienden que las palabras de concordia y de paz no deben servir para ocultar los sentimientos de rencor y de exterminio. Malaventurados los que en el gobierno ocultan tras la bondad de las palabras, la impiedad contra los hombres de su pueblo, porque ellos serán señalados con el dedo de la ignominia en las páginas de la historia". 
relembrando ideias do líder liberal morto durante a realização da IX Conferencia Panamericana e cujo assassinato deu início às manifestações violentas do que ficou internacionalmente conhecido como Bogotazo, acirrando os enfrentamentos entre liberais e conservadores, gerando distúrbios, saques e conflitos armados na capital e tomando proporções que alcançaram grande parte do país. A participação de alguns intelectuais de diferentes tendências políticas (liberais, socialistas, comunistas, opositoras ao governo) ocupando emissoras de rádio e difundindo proclamas que tentavam criar juntas revolucionárias populares para tomarem o poder de maneira ordenada, ou simplesmente procurando orientar a população que agia sem organização durante os distúrbios cujo caso mais famoso e controverso foi o da tomada da Radiodifusora Nacional - também foi relembrada pela revista uma vez que o jovem Jorge Gaitán Durán estava entre os "radioamotinados". Evidentemente, buscando relevar a participação do fundador da revista num episódio importante da história da Colômbia, Mito reproduz também em seu $\mathrm{N}^{0} 18$ (o texto havia sido publicado originalmente no semanário La Calle) o testemunho de Gaitán Durán sobre o caso, intitulado "Diez años después". 25

Essa atualização e recontextualização do tema de la Violencia publicada nas páginas de uma mesma edição de Mito (a de $N^{\circ} 18$, ainda que sob a forma de notas em suas últimas páginas), tanto através do discurso de Jorge Eliécer Gaitán como do texto de Gaitán Durán, servem para exemplificar o hábil recurso político adotado para o posicionamento da revista diante da candidatura de Alberto Lleras e o começo dos governos da Frente Nacional em 1958, já que junto a tais textos também foram publicadas as notas de Pedro Gómez Valderrama (apoiando abertamente o movimento da Frente) e de Gaitán Durán (apoiando com ressalvas céticas). Mito assim legitimava a necessidade conciliadora da Frente Nacional ao rememorar o Bogotazo e o duro processo de violência e intolerância atravessado pelos colombianos nos últimos dez anos,

25 DURÁN, Jorge Gaitán. Diez años después. Mito - revista bimestral de cultura, Bogotá, № 18 , p. 496, fev.-mar.-abr. 1958. Neste texto podemos ler: “[...] Cuando llegué, el personal de la Radio Nacional estaba aterrado y comenzaba a huír. Fue así como unos pocos estudiantes y yo quedamos dueños de la más importante radiodifusora del país, sin disparar un tiro. [...]. Durante cierto tiempo intentamos poner en marcha aparatos que desconocíamos. Cuando lo logramos, ya la Radio Nacional estaba llena de individuos con inconfundible aspecto de hampones, con quienes tuvimos que sostener una empeñosa lucha por la posesión de los micrófonos. Comunicados absurdos y discursos imbéciles se sucedieron vertiginosamente. Esta situación duró hasta la llegada de Jorge Zalamea, a quien de manera tan ignominiosa se ha calumniado por su comportamiento de ese día. Fue el único que tuvo la lucidez y la autoridad suficientes para proponer un programa insurreccional concreto y un poco de orden". 
demonstrando uma mudança da postura distanciada do partidarismo em seus primeiros números para uma postura que se aproximava de uma estreiteza partidária, ainda que sob a forma híbrida de uma conciliação forçada e desesperada entre liberais e conservadores que foi o surgimento da Frente Nacional.

Em 1948, a presença da IX Conferencia Panamericana fez com que a crise corresse o risco de tomar proporções internacionais. Diante de visível embaraço e numa tentativa de manter as aparências ante a opinião internacional, o governo colombiano começou a divulgar que os incidentes haviam sido causados por motivação comunista vinda do exterior ${ }^{26}$, provavelmente com apoio de liberais colombianos de tendências esquerdistas. Apesar disso, em nenhum momento ficou comprovada a responsabilidade de organizações comunistas pelo assassinato do líder liberal, fato que não convenceu a direita colombiana, que, a partir desse dia, passou a estimular ainda mais os ódios partidaristas. ${ }^{27}$

\section{ANTITOTALITARISMO E A VIOLÊNCIA}

Após o fechamento do Congresso Nacional em novembro de 1949 por Ospina Pérez, foi declarado estado de sítio no país, situação de privações de direitos cuja implicação mais conhecida foi o estabelecimento da censura à imprensa e à radiodifusão. O estado de sítio permaneceu vigente ininterruptamente durante o fim do mandato de Pérez, todo o mandato de Laureano Gómez (e, por conseguinte, o de Urdaneta Arbeláez), alcançando o início do governo de Rojas Pinilla. Este período de supressão sistemática de garantias constitucionais e repressões políticas e sociais poderia nos levar a afirmar que Colômbia viveu até o fim do governo militar de Rojas Pinilla sob sistemas de

${ }^{26}$ O fato é que teve início nessa época uma verdadeira caça aos comunistas no continente, um dos maiores reflexos da Guerra Fria, e que proporcionou injustas perseguições a alguns intelectuais, como, por exemplo, no caso que se passava em Colômbia, a que ocorreu ao escritor Luis Cardoza y Aragón, acusado de ser um dos responsáveis pela revolta, pelo simples fato de ser delegado representante na conferência do governo progressista de Jacobo Arbenz. Um dos maiores acusadores do poeta guatelmateco foi Enrique Santos Montejo, "Calibán", que em sua coluna "Danza de las Horas" no jornal El Tiempo atribuiu a ele a missão de matar a George Marshall. Apud MÁRQUEZ, Gabriel García. Vivir para contarla. (3 $3^{\mathrm{a}}$ ed.). Buenos Aires: Sudamericana, 2002, p. 355.

27 Mais tarde, quando se divulgou que Fidel Castro esteve presente em Bogotá durante aqueles dias, a teoria de conspiração comunista tomou força. Mas, como se sabe, o na época jovem estudante cubano de 21 anos ainda não era comunista e havia ido a Bogotá como delegado de um congresso estudantil que, ainda que contrário à conferência, não chegava a provocar uma conspiração. Apud ALAPE, Arturo. El Bogotazo, memorias del olvido. Bogotá: Planeta/XXVII, 1994, p. 370-375. 
ditaduras civil e militar ${ }^{28}$, condições de restrições democráticas que influenciaram diretamente o discurso reivindicador das liberdades de expressão assumido por Mito durante seus dois primeiros anos que coincidiram com os dois finais do general Pinilla.

Se durante o governo de Pérez ocorreram tentativas (ainda que efêmeras) de diálogo entre os partidos (como os dois momentos de colaboração administrativa), já no governo de Laureano Gómez a intransigência política alcançou níveis extremos:

Con un movimiento sindical deshecho, con una persecución que se refinaba a medida que la policía y el ejército se iban conformando con copartidarios y se depuraban de contrarios, Gómez, desde el poder emprendió sus sueños corporativistas tantas veces deseados y prosiguió la persecución y eliminación de sus contrarios a los cuales englobó dentro de una misma categoría: comunistas, masones, o liberales. $^{29}$

Em muitas regiões do país, além da violência política partidarista, conflitos armados se generalizaram devido a disputas agrárias de diversas índoles, a lutas pelo controle de estruturas locais de poder, vinganças ou aos denominados "bandolerismos". A desintegração social em muitas áreas do país contou com a organização de grupos armados guerrilheiros de inspiração liberal e comunista, como os do sul do estado de Tolima e os dos Llanos Orientales. ${ }^{30}$ Poucos anos depois, na entrega No 25 (jun.-jul. 1959), a revista Mito publicou a pesquisa de opinião "La responsabilidad de los intelectuales ante la violencia", e dentre os textos encontra-se o de Juan Lozano y Lozano, "Guerrilleros y bandoleros", que reconta um elucidativo diálogo ocorrido entre o ex-Presidente liberal Alfonso López, que havia aceitado o convite do governo para viajar aos Llanos para averiguar as condições de pacificação, e o então designado conservador Urdaneta Arbeláez, que esperava seu informe, diálogo este em que podemos ver as diferentes perspectivas políticas com que eram tratados os conflitos armados:

${ }^{28}$ BUSHNELL, David. La era de la Violencia (1946-1957), op.cit.

${ }^{29}$ MEJÍA, Alvaro Tirado. Colombia: siglo y medio de bipartidismo, op. cit., p. 166. O caso de Jorge Zalamea e seu periódico Crítica (1948-1951) enquadrou-se nesta "categoria" como um dos mais conhecidos exemplos de perseguição e patrulhamento ideológico.

30 Mais tarde, em 1964, o sul de Tolima e o norte do Valle del Cauca seriam os berços das Farc (Fuerzas Armadas Revolucionarias de Colombia), como uma evidente consequência da ininterrupta luta armada na região em torno de questões territoriais indígenas e de direitos políticos pelos camponeses, conflitos tais que se prolongaram desde os inícios do período de la Violencia. A história de luta de seu fundador Manuel Marulanda Vélez, conhecido como Tirofijo, exemplifica um resultado direto deste processo de guerrilha revolucionária marxista. 
"Qué dicen los bandoleros?", le preguntó Urdaneta [...]. "Yo no se qué digan los bandoleros", contestó López, "ni los conozco; ni, de conocerlos, me prestaría a hablar con ellos; ni los gobiernos pueden enviar embajadas ante los bandoleros. Si a usted le interesa saber lo que piensan los guerrilleros, pasaré a informarle". ${ }^{31}$

Após o golpe de Estado levado a cabo pelo general Rojas Pinilla em junho de 1953, este conseguiu dar significativos passos em torno da amenização da violência no começo de seu governo, sendo a anistia aos guerrilheiros liberais dos Llanos Orientales seu maior êxito político nesse sentido, ainda que opiniões como a de Jorge Gaitán Durán procuraram enxergar a questão sob outra óptica, como a expressa no "Diálogo sobre las guerrillas del Llano" entre Gaitán Durán e o ex-guerrilheiro e escritor Eduardo Franco Isaza no No 15 da revista Mito:

\begin{abstract}
Considero que no se ha comprendido la importancia de las guerrillas en la vida nacional. Las guerrillas del Llano 'pudrieron' la dictadura neciamente reaccionaria antes del 13 de junio de 1953, como luego las del Tolima 'pudrieron' la dictadura militar. En ambos casos significaron — digámoslo así - una llaga, que no permitió la estabilización en el país de los regímenes de fuerza. Aunque ello asombre a nuestros dirigentes, la violencia defensiva de las guerrillas abrió el camino a la cooperación de nuestros dos partidos tradicionales, al demostrar que una minoría no podía gobernar por la fuerza. ${ }^{32}$
\end{abstract}

Importante ainda frisar que Mito destacou obras significativas da literatura gerada junto à violência dos conflitos armados como, por exemplo, o romance do próprio Eduardo Franco Isaza, Las guerrillas del Llano, de 1955, resenhado em duas oportunidades em suas páginas; ou publicado na íntegra o romance de Gabriel García Márquez, El coronel no tiene quien le escriba (Mito, No 19, 1958, p. 1-38); e que no ano de 1962 inclusive publicaria através de Ediciones Mito o romance La casa grande, de Álvaro Cepeda Samudio. ${ }^{33}$

31 LOZANO, Juan Lozano y. Guerrilleros y bandoleros. Mito - revista bimestral de cultura, Bogotá, n. 25, p. 41, fev.-mar.-abr. 1959.

32 DURÁN, Jorge Gaitán; ISAZA, Eduardo Franco. Diálogo sobre las guerrillas del Llano. Mito revista bimestral de cultura, Bogotá, № 15, p. 199-200, ago.-set. 1957.

${ }^{33}$ Augusto Escobar Mesa, em seu texto "Literatura y violencia en la línea de fuego" (In: Ensayos y aproximaciones a la otra literatura colombiana. Bogotá: Universidad Central, 1997), propõe a distinção entre uma literatura que "sigue paso a paso los hechos históricos" ("novelas de la violencia") e uma que "hace una reflexión más crítica de éstos, vislumbrando una nueva opción estética y, en consecuencia, una nueva manera de aprehender la realidad" ("novelas sobre la violencia"), identificando o ano de 1958, quando aparece El coronel no tiene quien le escriba na revista Mito, como data divisora entre o primeiro e o segundo tipo de narrativas. 
A campanha ideológica de Rojas Pinilla, mesmo que longe de um consenso, foi considerada pela maioria da opinião pública como um resultado satisfatório, mas as controvérsias acerca de suas medidas administrativas não demoraram muito para emergirem. A natureza cada vez mais rígida de seu regime começou a gerar certo desconforto nos partidos, ainda mais depois de declarar o Partido Comunista ilegal por motivos de resistências armadas de partidários e simpatizantes camponeses em algumas regiões que foram consideradas como "zonas de guerra". A anistia aos guerrilheiros liberais não ocorreu com os comunistas e o recrudescimento de la Violencia se deu diante de crescentes ações arbitrárias do governo.

\section{LIBERDADE TOTAL}

Em abril e maio de 1955, meses em que se deu o começo da publicação de Mito - revista bimestral de cultura, a situação política na Colômbia era muito difícil. Como aqui já mencionamos, nos primeiros meses de sua existência (a partir de agosto) Mito se deparou com os danos à liberdade de imprensa ocorridos pela suspensão dos principais jornais do país em 1955. A revista se pronunciou em notas sobre o assunto em duas ocasiões: a primeira intitulada "Libertad de expresión" no № 4 (out.-nov. 1955, p. 275); e a segunda sob o título "Libertad de expresión (II)" no No 5 (dez. 1955-jan. 1956, p. 381), sendo ambas publicadas novamente em seu No 13 (mar.-abr.-maio 1957, p. 3) na compilação que Mito fez de textos sobre este tema, denominado “'Mito' y las libertades" (p. 1-9). Tais pronunciamentos não deixaram de também evidenciar uma gradual perda do controle governamental do Presidente Rojas Pinilla que, com o crescimento da oposição à sua administração, passou a ser denominado como ditador. A recusa de muitos grupos guerrilheiros em aceitar sua oferta de paz acabou desatando um enfurecimento do general Pinilla, e suas operações de combate afetaram milhares de inocentes, assim selando a sorte de sua presidência que descumpria sua maior promessa: a de justamente terminar com la Violencia, que naquelas alturas já detinha o assustador número de cerca de 200 mil mortos.

Como pudemos notar, mesmo que através dessa breve incursão por exem-

Apud Osorio, Óscar. Siete estudios sobre la novela de la Violencia en Colombia, una evaluación crítica y una nueva perspectiva, Poligramas, № 25, p. 97-100, junho 2006. 
plos da maneira como Mito buscou discutir alguns dos importantes acontecimentos políticos de sua época e dos diretamente anteriores, não apenas por meio de uma reflexão passiva ou contemplativa da história e suas implicações, mas, sobretudo, por meio de uma postura engajada com a realidade sociocultural colombiana, frontal em seus posicionamentos e de característica participativa, tal forma de atuação nos permite procurar compreender os aportes intelectuais à cultura do país também a partir de uma necessária abordagem que discuta "política" e "cultura" de forma integrada e interdependente. Agindo dentro desse "continuum", nos parece significativo ressaltar que Mito se ocupou extensamente de temas tanto nacionais como internacionais que evidentemente se estabeleciam nesse entremeio político-cultural, como, para citar apenas alguns exemplos, os casos concernentes à religião (a entrevista com o futuro padre guerrilheiro Camilo Torres - No 12; a "radiografia" da Opus Dei No 16); à educação (a participação dos estudantes na queda de Rojas Pinilla $N^{\circ} 13$; o veto sobre o trabalho de Gerardo Molina na Universidad Libre - $N^{\circ}$ 10); à violência (os aqui mencionados debates em torno do livro Las guerrillas del Llano, de Eduardo Franco Isaza - No 3 e No 15, ou das responsabilidades dos intelectuais ante a violência - $N^{\circ} 25$ ); à sexualidade (os textos de Sade $-N^{\circ} 1$ e $N^{\circ} 17$; de Georges Bataille - No 27-28; o informe Kinsey - No 3 e No 7; o relato "A história clínica de um homossexual" - No 22-23); ou à liberdade de expressão, tema a que Mito esteve constantemente atenta (o número extraordinário "Libertades totales" publicado em 10 de maio de 1957; a reaparição dos jornais El Tiempo e El Siglo também em 1957 - No 13; as restrições democráticas na Venezuela - $\mathrm{N}^{\circ} 16 \mathrm{e}-\mathrm{N}^{\circ} 17$; a censura francesa aos periódicos - entre eles à revista Les Temps Modernes - pelos artigos sobre a guerra na Argélia - $N^{\circ} 17$; a prisão do escritor espanhol Luis Goytisolo - No 27-28 e N²9), dessa maneira demonstrando como a atuação "cultural" pode ser considerada estrategicamente como proporcionadora de efeito "político".

Os casos aqui referidos neste artigo, sobretudo os de significância nacional, se por um lado demonstram a habilidade e perspicácia do grupo responsável pela revista Mito em se posicionar e interferir diretamente nas questões históricas de sua época, por outro apontam para a contemporaneidade dos temas por ela abordados (intolerância, violência, conflito armado... apesar de passado mais de meio século desde o fim de sua publicação), através de uma política editorial precisa cuja perspectiva de atuação soube identificar em tais assuntos os conflitos cruciais que necessitavam (e em alguns casos ainda necessitam) de soluções para o benefício do povo colombiano. 